\title{
Desempenho de trator agrícola em três superfícies de solo e quatro velocidades de deslocamento
}

\author{
Antonio Gabriel Filho', Keber P. Lanças ${ }^{2}$, Fabrício Leite', Juan J. B. Acosta ${ }^{3} \&$ Paulo R. Jesuino ${ }^{4}$
}

\section{RESUMO}

0 objetivo desse trabalho foi avaliar a capacidade de um trator em desenvolver força de tração ao tracionar uma carga de $25 \mathrm{kN}$ em quatro velocidades de deslocamento e em três condições da superfície do solo: solo mobilizado, solo coberto com os restos da cultura do milho e braquiária e solo firme sem cobertura. 0 experimento foi realizado em três faixas representadas pelo tipo de superfície, sendo aplicados os quatro tratamentos determinados pela velocidade de deslocamento, obtidos pelas mudanças de marchas do trator. Utilizaram-se seis repetições em cada faixa, totalizando 72 unidades experimentais, monitorando-se a velocidade de deslocamento, a força de tração, a patinagem das rodas traseiras e dianteiras e o consumo horário de combustível. A análise dos resultados permitiu concluir que no solo firme e sem cobertura vegetal, o desempenho do trator foi melhor, seguido pelo solo com a superfície coberta com palha de milho e braquiária e, por último, 0 solo com a superfície mobilizada. 0 melhor desempenho do trator foi obtido na macha C1 que forneceu a velocidade de deslocamento de $6 \mathrm{~km} \mathrm{~h}^{-1}$.

Palavras-chave: máquina agrícola, ensaio, tração

\section{Performance of agricultural tractor on three different soil surfaces and four forward speeds}

\begin{abstract}
The aim of this work was to evaluate tractor performance in soil with three different surfaces: firm soil without covering, mobilized soil, and firm soil with vegetal residue of corn and braquiária, for four forward speeds. The experiment was accomplished in three plots determined by the soil conditions. In each plot four treatments were composed by the forward speed obtained by the changes of the tractor gear. Six repetitions were used in each plot, totaling 72 experimental units, combination of the traction, slip of the rear and front wheels, forward speed and fuel consumption. The values of the tractor performance obtained led to the conclusion that in the firm soil without vegetable covering the tractor performance was better, followed by the soil with the firm surface and covered with corn straw and braquiária and finally the mobilized soil. The best tractor performance was obtained in the C1 gear that supplied the forward speed of $6 \mathrm{~km} \mathrm{~h}^{-1}$.
\end{abstract}

Key words agricultural machine, test, traction

\footnotetext{
${ }^{1}$ Centro de Ciências Exatas e Tecnológicas/U N IO ESTE, CEP 85605-010, Cascavel, PR. Fone: (045) 3220-3199. E-mail: gabriel@unioeste.br

2 Departamento de Engenharia Rural/UN ESP/Botucatu, SP, CEP 18618-000. Fone: (14) 3811-7165. E-mail: kplancas@fca.unesp.br

3 CCA/U EM, CEP 87506-370, U muarama, PR. Fone: (44) 3621-9411. E-mail: fleitez@vem.br

${ }^{4}$ Mestrando em Agronomia, DER/UN ESP. Fone: (14) 3811-7165. E-mail: paulojesuino@fca.unesp.br
} 


\section{INTRODUÇÃO}

Uma das principais funções dos tratores agrícolas é transformar a energia contida no combustível e fornecê-la, através da barra de tração, para tracionar máquinas e implementos agrícolas.

O desempenho na barra de tração de um trator depende, principalmente, da potência do motor, dos mecanismos de transmissão, da distribuição de peso sobre os rodados, da altura e posição dos engates da barra e da superfície do solo.

Entre os fatores que interferem na tração, a condição da superfície do solo também é importante e, dentre as propriedades do solo que afetam a eficiência de tração de um trator agrícola, pode-se mencionar a textura do solo, a umidade desse solo e as condições da superfície, dependendo da cobertura existente sobre o solo (Yanai et al., 1999).

Na transmissão de potência do motor para a barra de tração ocorrem perdas que, dependendo das condições de operação do trator, podem atingir níveis bastante comprometedores. Estimativa da perda de potência, segundo Zoz (1987), nos diferentes mecanismos do trator e diferentes condições de solo para tratores $4 \times 2$ podem variar de $20 \%$ em pistas de concreto até $53 \%$ ou mais em solo cuja condição de tração é pobre (solo solto).

Gabriel Filho et al. (2004) avaliaram o desempenho operacional de um trator agrícola em área com diferentes tipos de cobertura vegetal, concluindo que a maior quantidade de matéria seca na superfície do solo tende a aumentar os índices de patinagem e, assim, diminuir a eficiência de tração.

De acordo com Cordeiro (2000), a avaliação direta do desempenho de tratores em condições de campo é obtida através da instrumentação e monitoramento dos tratores, permitindo a determinação de fatores diretamente relacionados com a eficiência de trabalho do trator. $\mathrm{O}$ autor realizou um estudo do desempenho de um trator agrícola em função do pneu, da lastragem e da velocidade de deslocamento e concluiu que estes fatores alteraram significativamente a conversão energética, a patinagem e a força de tração.

A velocidade de deslocamento altera o desempenho do trator visto que afeta diretamente o consumo de combustível. Lopes et al. (2003) avaliaram o consumo de combustível de um trator em função da velocidade de trabalho e observaram que o aumento da velocidade de deslocamento reduziu o consumo específico.

A eficiência em realizar a tração depende de um complexo conjunto de fatores que envolvem a interação do rodado com o solo. Para quantificar ou predizer esses mecanismos de interação rodado-solo, numerosos modelos tem sido propostos. Wismer \& Luth (1974) desenvolveram uma equação largamente utilizada para predizer a eficiência de tração em condições de solo para pneus de constituição diagonal. Alterações na equação de Wismer \& Luth (1974) foram propostas, ao longo dos anos, por vários autores. Atualmente, a equação proposta por Brixius (1987) é a mais utilizada, sendo adotada pela American Society of Agricultural Engineers (ASAE, 1999b).

Neste trabalho se objetivou quantificar as variáveis relacionadas com a tração de um trator operando em solo com três condições de superfície: mobilizada; firme, porém coberta com os restos da cultura de milho e braquiária e firme sem cobertura; além disso, foram selecionadas quatro marchas do trator que proporcionam suas velocidades de deslocamento mais usuais e que requerem maiores forças de tração.

\section{MATERIAL E MÉTODOS}

O experimento foi desenvolvido na Fazenda Experimental Lageado, pertencente à Faculdade de Ciências Agronômicas da Universidade Estadual Paulista, Campus de Botucatu em uma área localizada nas coordenadas $22^{\circ} 51^{\prime} \mathrm{S}$ e $48^{\circ} 25^{\prime} \mathrm{W}$ e a altitude do local é de $770 \mathrm{~m}$.

O solo da área experimental, classificado de acordo com a EMBRAPA (1999), foi um Latossolo Vermelho com relevo plano e textura argilosa.

Os ensaios foram realizados em três faixas de solo, denominadas pistas, com $400 \mathrm{~m}$ de comprimento e $20 \mathrm{~m}$ de largura cada, totalizando $24.000 \mathrm{~m}^{2}$. A declividade das pistas era de $0,3 \%$ no sentido do comprimento e niveladas na largura.

Foi utilizado o delineamento experimental em faixas (Gomes, 1982; Banzatto \& Kronka, 1995; Gomes \& Garcia, 2002), com três faixas definidas pelas condições da superfície do solo; assim, a primeira teve a superfície escarificada e gradeada, a segunda superfície estava coberta com os restos da cultura do milho e braquiária (Brachiaria decumbens), sem movimentação do solo e na terceira faixa a superfície foi mantida descoberta e firme. Em cada faixa foram dispostos, em blocos aos acaso, os tratamentos definidos pelas quatro velocidades de deslocamento determinadas pela mudança de marcha. Para cada tratamento foram utilizados seis repetições, sendo 24 unidades experimentais para cada faixa e 72 no total.

A mobilização do solo da primeira pista foi realizada com um escarificador de cinco hastes com rolo destorroador para romper a camada compactada e em seguida uma grade média foi utilizada para o destorroamento da superfície.

Na segunda pista (pista central) foi realizada a dessecação da vegetação composta principalmente por braquiária e, em seguida, semeado milho sob a palha no início de dezembro de 2005. Antes de iniciar a colheita, foi necessário mais uma dessecação para combater a braquiária que germinou durante a fase final de produção do milho. A colheita foi realizada em maio de 2006 com uma colhedora automotriz e, para maior uniformidade da distribuição da palha, utilizou-se um ancinho enleirador/espalhador para distribuir a palha acumulada.

Na pista com solo firme (terceira pista), foram realizados dessecações da vegetação presente no local e, próximo ao período do ensaio, empregou-se uma moto-niveladora para uniformizar a superfície e retirar os restos da vegetação.

Os trabalhos foram realizados com um trator John Deere 6600 de $88 \mathrm{~kW}(120 \mathrm{cv})$ de potência no motor a 2100 rotações por minuto do motor e com a tração dianteira auxiliar ligada. A Tabela 1 mostra as características ponderais e a massa do trator. 
As marchas A3, B1, B2 e C1, que correspondem às velocidades sem carga de 4, 5, 7 e $8 \mathrm{~km} \mathrm{~h}^{-1}$, respectivamente, conforme consta no painel do trator foram selecionadas.

Para fornecer força na barra de tração foi utilizada a Unidade Móvel de Ensaio na Barra de Tração - UMEB, desenvolvida pelo Núcleo de Ensaio de Máquinas e Pneus Agroflorestais - NEMPA. A UMEB foi construída a partir de um reboque tipo casa (trailer), reformado e adaptado para servir como um carro dinamométrico instrumentado, utilizado na avaliação do desempenho de trator submetido a ensaio de tração. Sua massa total era de $9.000 \mathrm{~kg}$ sustentada por um conjunto de quatro rodados duplos. O sistema de frenagem era pneumático o que facilitou o controle de esforço necessário para a tração.

Tabela 1. A características ponderais e a massa do trator John D eere 6600

\begin{tabular}{lc}
\hline \multicolumn{1}{c}{ Característica } & Valores \\
Distância entre eixos $(\mathrm{mm})$ & 2.640 \\
Altura da barra de tração $(\mathrm{mm})$ & 465 \\
Carga estática sobre o rodado $-\mathrm{kg}(\%)$ & \\
Dianteiro & $2.752(41 \%)$ \\
Traseiro & $3.971(59 \%)$ \\
TOTAL & $6.723(100 \%)$ \\
\hline
\end{tabular}

Para determinação da densidade das partículas, da densidade do solo, da granulometria e dos limites de Atterberg, utilizou-se a metodologia proposta por EMBRAPA (1997) e Kiehl (1979), sendo a amostragem de solo realizada entre 5 e $10 \mathrm{~cm}$ de profundidade.

Amostragens de teor de água do solo foram realizadas nas camadas de 0 a $10 \mathrm{~cm}$ e 10 a $20 \mathrm{~cm}$, com 10 repetições por faixa.

Para determinar a resistência do solo à penetração, foi utilizada a UMAS - Unidade Móvel de Amostragem de Solo desenvolvido pelo NEMPA - Núcleo de Ensaio de Máquinas e Pesquisa Agroflorestais. Foram realizadas dez repetições por faixa, de forma aleatória, obtendo-se os resultados do índice de cone na camada de 0-15 cm.

A quantidade de matéria seca na superfície do solo foi determinada através de amostras retiradas na pista coberta com palha de milho e braquiária. Para retirada das amostras utilizou-se um quadrado de madeira de 0,25 m de lado em três repetições por parcela. As amostras foram recolhidas em sacos de papel e colocadas para secar em estufa a $62{ }^{\circ} \mathrm{C}$, durante $48 \mathrm{~h}$.

Os valores médios da granulometria, limites de Atterberg, densidade, umidade, índice de cone e massa de matéria seca da palhada de milho e braquiária, na pista coberta com restos de vegetação estão apresentados na Tabela 2 .

Em ensaios prévios se estabeleceu a força de $25 \mathrm{kN}$ a ser exercida pela UMEB na barra de tração do trator, pois nessa carga a patinagem das rodas ficou próxima de $15 \%$ em solo solto e $8 \%$ em solo coberto e em solo firme, conforme recomendado pela bibliografia (Lanças, 1996).

Os sinais obtidos pelos sensores instalados nos rodados na tomada de potência, no sistema de alimentação e na barra de tração, foram registrados em um painel eletrônico com
Tabela2. Dados do solo retirado nas pistas com o solo mobilizado (SM), com solo coberto com palha (CP) e solo firme (SF)

\begin{tabular}{|c|c|c|c|}
\hline Característica & Pista SS & Pista CP & Pista SF \\
\hline Areia (\%) & 38,30 & 40,96 & 41,88 \\
\hline Silte (\%) & 18,87 & 16,92 & 17,11 \\
\hline Argila (\%) & 42,83 & 42,12 & 41,01 \\
\hline Limite de liquidez (\%) & 33,45 & 31,76 & 31,99 \\
\hline Limite de plasticidade (\%) & 25,81 & 26,16 & 25,32 \\
\hline Densidade dos sólidos $\left(\mathrm{g} \mathrm{cm}^{-3}\right)$ & 3,00 & 3,10 & 2,99 \\
\hline Densidade do solo $\left(\mathrm{g} \mathrm{cm}^{-3}\right)$ & - & 1,31 & 1,63 \\
\hline \multirow{3}{*}{$\begin{array}{l}\text { Umidade }(\%): \quad 10-20 \mathrm{~cm} \\
\text { Índice de cone }(\mathrm{kPa}) 0-15 \mathrm{~cm}\end{array}$} & 19,09 & 21,85 & 19,46 \\
\hline & 19,81 & 22,01 & 19,78 \\
\hline & 750 & 1.684 & 3629 \\
\hline Massa de matéria seca $\left(\mathrm{kg} \mathrm{ha}^{-1}\right)$ & - & 10.089 & - \\
\hline
\end{tabular}

visores mostrando os dados obtidos. Esses sinais também foram enviados a um sistema de aquisição eletrônico de dados (Micrologger CR23X), para serem armazenados; tanto o painel quanto o sistema eletrônico de aquisição de dados foram instalados dentro da UMEB.

Os transdutores, do tipo analógico (célula de carga) e de pulso (patinagem e medidor de consumo), foram alimentados com uma bateria ligada ao Micrologger e monitorados a uma frequência de aquisição de $2 \mathrm{~Hz}$, previamente definida por programação.

Foram monitorados, também, as forças de tração, a patinagem das rodas traseiras e dianteiras dos tratores, as velocidades de deslocamento e o consumo horário de combustível, cujos dados foram, posteriormente, transferidos para um computador, para tabulação e análise.

Para determinar o requerimento de força na barra de tração, empregou-se uma célula de carga marca SODMEX, modelo N400, com sensibilidade de 2,156 mV/V e capacidade para $100 \mathrm{kN}$, instalada em um "berço" acoplado ao trator.

Com os valores obtidos a força de tração média foi determinada pela Eq. 1.

$$
\mathrm{F}_{\mathrm{m}}=\frac{\sum_{\mathrm{i}=1}^{\mathrm{n}} \mathrm{Fi}}{\mathrm{n}}
$$

em que:

$$
\begin{gathered}
\mathrm{F}_{\mathrm{m}} \text { - força de tração média, } \mathrm{kN} \\
\mathrm{F}_{\mathrm{i}} \text { - força de tração instantânea, } \mathrm{kN} \\
\mathrm{n} \text { - número de dados registrados }
\end{gathered}
$$

A velocidade de deslocamento foi determinada medindose o tempo necessário para percorrer as parcelas de $25 \mathrm{~m}$ de comprimento. Em cada extremidade da parcela foi colocada uma baliza para que o cronometrista pudesse determinar o momento exato em que o trator iniciou e terminou o percurso; enfim os valores da velocidade foram expressos em $\mathrm{km} \mathrm{h}^{-1}$.

A determinação da patinagem das quatro rodas do trator foi realizada com os dados dos geradores de pulsos instalados em cada roda, modelo GIDP-60-U-12V, que geram 60 pulsos por volta. A patinagem foi obtida através das rotações do rodado com e sem carga e determinada pela Eq. 2. 


$$
\text { Pat }=100 \cdot \frac{\mathrm{n}_{1}-\mathrm{n}_{0}}{\mathrm{n}_{0}}
$$

em que:

Pat - patinagem das rodas, \%

$\mathrm{n}_{0}$ - número de pulsos da roda sem carga

$\mathrm{n}_{1}$ - número de pulsos da roda com carga

O consumo de combustível foi determinado utilizando-se um medidor de fluxo FLOWMATE M-III modelo LSN40, instalado no sistema de alimentação do trator, conforme descrito em Cordeiro (2000). Os pulsos gerados pelo medidor foram convertidos em volume considerando a frequência de $1 \mathrm{~mL}$ por pulso. O cálculo do consumo horário foi realizado segundo a Eq. 3.

$$
\mathrm{CH}=\frac{\mathrm{Np} \times 3,6}{\mathrm{t}}
$$

em que:

$\mathrm{CH}$ - consumo horário, $\mathrm{L} \mathrm{h}^{-1}$

$\mathrm{Np}$ - número de pulso do medidor de combustível

$\mathrm{t}$ - tempo de percurso da parcela, $\mathrm{s}$

Mediu-se a temperatura do combustível com um termômetro de platina tipo PT100 instalado no sistema de alimentação do trator, próximo ao medidor de fluxo.

A densidade do combustível foi determinada conforme descrito por Grotta (2003) e os valores obtidos foram utilizados para o cálculo do consumo específico.

A potencia disponível na barra de tração foi obtida em função da força de tração e da velocidade de deslocamento, de acordo com a Eq. 4.

$$
\mathrm{Pb}=\frac{\mathrm{Fm} \times \mathrm{V}}{3,6}
$$

em que:

$\mathrm{Pb}$ - potência na barra, $\mathrm{kW}$

Fm - força de tração média, $\mathrm{kN}$

$\mathrm{V}$ - velocidade de deslocamento, $\mathrm{km} \mathrm{h}^{-1}$

O consumo específico de combustível foi obtido em função do consumo horário e da potência na barra, segundo a Eq. 5.

$$
\mathrm{Ce}=\frac{\mathrm{CH} \times \mathrm{Dc}}{\mathrm{Pb}}
$$

em que:

Ce - consumo específico de combustível, g kW h-1

$\mathrm{CH}$ - consumo horário de combustível, $\mathrm{L} \mathrm{h}^{-1}$

Dc - densidade do combustível, $\mathrm{g} \mathrm{dm}^{-3}$

$\mathrm{Pb}$ - potência na barra, kW

O consumo específico foi determinado considerando a temperatura do combustível após a passagem em cada uma das parcelas.

Obtiveram-se os valores da carga dinâmica conforme a Eq. 6, em função da carga estática sobre os rodados traseiros e da transferência de peso.

$$
\mathrm{Cd}=\mathrm{Ce}+\frac{\mathrm{Ft} \times \mathrm{y}}{\mathrm{De}}
$$

em que:

R. Bras. Eng. Agríc. Ambiental, v.14, n.3, p.333-339, 2010.
Cd - carga dinâmica sobre o rodado, $\mathrm{kN}$

$\mathrm{Ce}$ - carga estática sobre o rodado, $\mathrm{kN}$

$\mathrm{Ft}$ - força de tração média, $\mathrm{kN}$

$\mathrm{y}$ - altura da barra de tração, m

De - distância entre eixos, $m$

Os valores do coeficiente de tração foram obtidos pela Eq. 7.

$$
\mathrm{CT}=\frac{\mathrm{Ft}}{\mathrm{Cd}}
$$

em que:

CT - coeficiente de tração

$\mathrm{Ft}$ - Força de tração, kN

Cd - Carga dinâmica sobre os rodados, $\mathrm{kN}$

A resistência ao rolamento foi determinada, segundo Brixius (1987) e ASAE D 497.4 (ASAE,1999b), pela Eq. 8.

$$
\mathrm{RR}=\mathrm{Ft} *\left[(1 / \mathrm{Bn})+0,04+\left(\frac{0,5^{*} \mathrm{Pat}}{\sqrt{\mathrm{Bn}}}\right)\right]
$$

em que:

$$
\begin{aligned}
& \mathrm{RR} \text { - Resistência ao rolamento, kN } \\
& \mathrm{Ft} \text { - Forca de tração, kN } \\
& \mathrm{Pat} \text { - Patinagem das rodas, \% } \\
& \mathrm{Bn} \text { - Índice adimensional }
\end{aligned}
$$

Obteve-se o rendimento tratório em função da tração bruta e da tração líquida desenvolvida pelo trator através da Eq. 9, segundo Brixius (1987) e ASAE D 497.4 (ASAE, 1999b):

$$
\mathrm{RT}=(1-\mathrm{Pat}) *\left(\frac{\mathrm{TL}}{\mathrm{TB}}\right)
$$

em que:

RT - Rendimento tratório, \%

Pat - Patinagem das rodas, \%

TL - Tração líquida, kN, obtido pela Eq. 10

TB - Tração bruta, kN, obtido pela Eq. 11

sendo:

$$
\begin{aligned}
& \mathrm{TL}=\mathrm{Cd} *\left[\left(0,88^{*}\left(1-\mathrm{e}^{-0,1^{*} \mathrm{Bn}}\right) *\left(1-\mathrm{e}^{-7,5^{* \mathrm{Pat}}}\right)\right)-\left(\frac{1}{\mathrm{Bn}}\right)-\left(\frac{0,5^{*} \mathrm{Pat}}{\sqrt{\mathrm{Bn}}}\right)\right] \\
& \mathrm{TB}=\mathrm{Cd} *\left[0,88 *\left(1-\mathrm{e}^{-0,1^{*} \mathrm{Bn}}\right) *\left(1-\mathrm{e}^{-7,5^{* \mathrm{Pat}}}\right)+0,04\right]
\end{aligned}
$$

donde:

$$
\begin{aligned}
& \text { Cd - carga dinâmica, } \mathrm{kN} \\
& \text { e - base dos logaritmos neperianos } \\
& \text { Bn - índice adimensional } \\
& \text { Pat - Patinagem das rodas, \% }
\end{aligned}
$$

Os valores obtidos nos ensaios foram submetidos à análise de variância e as médias comparadas pelo teste de Tukey a $5 \%$ de probabilidade.

\section{RESULTADOS E DISCUSSÃO}

As velocidades obtidas para cada marcha do trator e utilizadas nos ensaios estão apresentadas na Tabela 3, na qual 
se constatou uma redução dos valores médios de velocidade obtidos com o trator tracionando uma carga de $25 \mathrm{kN}$ em relação aos valores apresentados no painel do trator, nas quatro marchas e nas três pistas.

Tabela 3. Valores médios das velocidades de deslocamento $\left.\left(\mathrm{km} \mathrm{h}^{\mathrm{h}}\right)^{-1}\right)$ do conjunto nas quatro marcha do trator com pneus diagonais nas três condições da superfície do solo (Pista)*

\begin{tabular}{ccccc}
\hline \multirow{2}{*}{ Pista } & \multicolumn{5}{c}{ Marcha } \\
\cline { 2 - 5 } 1 & A3 & B1 & B2 & C1 \\
2 & $3,35 \mathrm{a}$ & $3,61 \mathrm{a}$ & $4,90 \mathrm{a}$ & $5,82 \mathrm{a}$ \\
3 & $3,41 \mathrm{a}$ & $3,95 \mathrm{a}$ & $4,88 \mathrm{a}$ & $5,91 \mathrm{a}$ \\
\hline Média & $3,54 \mathrm{a}$ & $3,88 \mathrm{a}$ & $5,27 \mathrm{a}$ & $5,97 \mathrm{a}$ \\
\hline
\end{tabular}

* Médias com letras iguais (minúsculas nas colunas e maiúsculas na linha) não diferem entre si pelo teste de Tukey $(\mathrm{P}>0,05)$; Pista 1 - solo mobilizada; Pista 2 - solo firme e coberto com palha de milho e braquiária; Pista 3 - solo firme e descoberta

A análise geral dos resultados obtidos nas pistas para as variáveis de desempenho, representado pelo teste $\mathrm{F}$ da análise de variância, está apresentada nas Tabelas 4 e 5.

Tabela4. Valores do teste $F$ para a patinagem do rodado dianteiro (Pat.d), patinagem do rodado traseiro (Pat.t), consumo horário de combustível (Ch) e potência na barra de tração $(\mathrm{Pb})$ em relação aos fatores de variação bloco, tratamento $(V)$ e condições da superfície do solo (Pista)

\begin{tabular}{lcccc}
\hline Fonte & Pat.d & Pat.t & Ch & Pb \\
Bloco & 2,94 & 4,47 & $3,81^{*}$ & 0,63 \\
V & 1,93 & 3,77 & $2,50^{*}$ & $164,28^{\star *}$ \\
Blocos*V & 0,96 & 1,67 & 1,31 & 1,12 \\
Pista & $210,35^{\star *}$ & $358,38^{\star *}$ & $290,71^{\star *}$ & $4,62^{*}$ \\
Blocos*Pista & 1,24 & 2,11 & 1,64 & 1,79 \\
V*Pista & $3,83^{\star *}$ & $6,49^{\star *}$ & $5,18^{\star *}$ & 1,78 \\
\hline
\end{tabular}

* significativo a $5 \% ; * *$ significativo a $1 \%$

Tabela 5. Valores do teste $\mathrm{F}$ para o consumo específico de combustível (Ce), carga dinâmica sobre o rodado traseiro $(C d)$, coeficiente de tração $(C t)$, resistência ao rolamento $(\mathrm{Rr})$ e rendimento tratório $(\mathrm{Rt})$ em relação aos fatores de variação bloco, tratamento $(V)$ e condições da superfície do solo (Pista)

\begin{tabular}{|c|c|c|c|c|c|}
\hline Fonte & $\mathrm{Ce}$ & Cd & Ct & $\mathbf{R r}$ & Rt \\
\hline Bloco & 1,97 & 1,12 & 0,60 & 2,51 & 3,26 \\
\hline V & $19,74^{\star *}$ & $3.590,84^{* *}$ & 39,50 ** & $418,64^{\star *}$ & $4,06^{* *}$ \\
\hline Blocos*V & 0,70 & 1,61 & 1,87 & 1,34 & 1,15 \\
\hline Pista & $218,11^{* *}$ & 2,65 & 2,80 & $14.930,15^{\star \star}$ & 744,06 ** \\
\hline Blocos*Pista & 1,74 & 2,66 & 2,39 & 1,58 & 1,27 \\
\hline V*Pista & $7,66^{\star *}$ & 1,82 & 1,89 & $4,68 * *$ & 4,32 \\
\hline
\end{tabular}

** significativo a $1 \%$

Observa-se, nas Tabelas 4 e 5, que houve variação significativa do bloco apenas no consumo de combustível, mas a variância dos tratamentos, além do consumo de combustível, foi significativa também para: a potência na barra de tração, o consumo específico de combustível, a carga dinâmica sobre o rodado traseiro, o coeficiente de tração, a resistência ao rolamento e a eficiência trativa. Nas pistas, houve variação significativa na patinagem do rodado dianteiro, na patinagem do rodado traseiro, no consumo de combustível, na potência na barra de tração, no consumo específico de combustível, na resistência ao rolamento e na eficiência trativa. A análise da variância para a interação entre os tratamentos e as pistas, apresentou diferença significativa na patinagem do rodado dianteiro, na patinagem do rodado traseiro, no consumo de combustível, no consumo específico de combustível, na carga dinâmica sobre o rodado traseiro, no coeficiente de tração e na resistência ao rolamento. Yanai et al. (1999) e Gabriel Filho et al. (2004) também observaram que a cobertura do solo alterou o desempenho do trator.

A hipótese de que o desempenho do trator pode ser alterado por influência das condições da superfície do solo e pela mudança da velocidade de deslocamento foi confirmada pela variância dos valores obtidos, pois a maioria das variáveis relacionadas com o desempenho apresentou diferenças significativas. Resultados semelhantes foram obtidos por Cordeiro (2000).

As análises das variáveis de desempenho estudadas para as quatro marchas do trator, em cada condição de solo, estão apresentadas na Tabela 6.

$\mathrm{O}$ aumento gradual da velocidade de, aproximadamente, 3,5 $\mathrm{km} \mathrm{h}^{-1}$, obtido na marcha A3, até cerca de $6,0 \mathrm{~km} \mathrm{~h}^{-1}$, na marcha $\mathrm{C} 1$, não alterou significativamente a patinagem do trator. Para uma solicitação de 25 kN no solo com a superfície mobilizada o trator manteve a patinagem próxima de 15\%. Este nível de patinagem está de acordo com os valores sugeridos pela ASAE (1999a) para um melhor desempenho do trator.

Na marcha C1 o trator proporcionou a maior potência na barra de tração, indicando que, nesta marcha, houve um melhor aproveitamento da energia mecânica desenvolvida pelo motor do trator. A potência obtida na marcha B2 foi menor que na marcha C1 e nas marchas A3 e B1 foram obtidas os menores valores de potência. Contudo, o maior valor da potência obtida na marcha C1 ocorreu às expensas de maiores consumos de combustível e, de forma semelhante à potência, o consumo de combustível diminuiu com a diminuição da velocidade de deslocamento, isto é, o uso da marcha de menor velocidade acarretou um menor consumo de combustível.

Os dados da Tabela 6, para o solo mobilizado, apresentam um consumo específico de combustível significativamente menor para as marchas B2 e C1 em relação às marchas A3 e B1. Entre as marchas B2 e C1 não houve diferença significativa do consumo específico do mesmo modo que nas marchas A3 e B1. Confrontando os dados de consumo específico e os dados de consumo de combustível e potência na barra de tração nota-se que nas marchas B2 e C1 o trator apresentou o melhor desempenho em solo mobilizado.

As variáveis, carga dinâmica sobre o rodado traseiro, coeficiente de tração, resistência ao rolamento e eficiência tratória não apresentaram diferença significativa nas quatro marchas utilizadas nos ensaios para o solo mobilizado.

Na Tabela 6, para o solo firme e coberto com palha de milho e braquiária observa-se que os valores obtidos foram semelhantes para a patinagem do rodado dianteiro, traseiro e do trator. A média da patinagem do trator foi próxima de 
Tabela 6. Valores médios de patinagem do rodado dianteiro (Pat.d), patinagem do rodado traseiro (Pat.t), patinagem do trator (Pat), potência na barra de tração $(\mathrm{Pb})$ consumo horário de combustível $(\mathrm{Ch})$, consumo específico de combustível $(\mathrm{Ce})$, carga dinâmica sobre o rodado traseiro $(\mathrm{Cd})$, coeficiente de tração $(\mathrm{Ct})$, resistência ao rolamento $(\mathrm{Rr})$ e rendimento tratório $(\mathrm{Rt})$ em função da marcha e solo*

\begin{tabular}{|c|c|c|c|c|c|c|c|c|c|c|}
\hline Tratamento & $\begin{array}{l}\text { Pat.d } \\
(\%)\end{array}$ & $\begin{array}{l}\text { Pat.t } \\
(\%)\end{array}$ & $\begin{array}{l}\text { Pat } \\
(\%)\end{array}$ & $\begin{array}{c}\mathrm{Pb} \\
(\mathrm{kW})\end{array}$ & $\begin{array}{c}C h \\
\left(L h^{-1}\right)\end{array}$ & 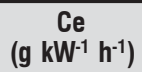 & $\begin{array}{l}\mathrm{Cd} \\
(\mathrm{kN})\end{array}$ & $\begin{array}{c}\mathrm{Ct} \\
\text { (adm.) }\end{array}$ & $\begin{array}{c}\mathrm{Rr} \\
(\mathrm{kN})\end{array}$ & $\begin{array}{c}\mathrm{Rt} \\
(\%)\end{array}$ \\
\hline \multicolumn{11}{|c|}{ No solo mobilizado } \\
\hline Marcha A3 & $15,26 \mathrm{a}$ & 15,43 a & $15,35 \mathrm{a}$ & 23,67 c & $13,88 \mathrm{c}$ & $488,52 \mathrm{a}$ & $42,04 \mathrm{a}$ & $0,61 \mathrm{a}$ & $4,26 \mathrm{a}$ & $0,74 \mathrm{a}$ \\
\hline Marcha B1 & $14,50 \mathrm{a}$ & $14,39 \mathrm{a}$ & $14,45 \mathrm{a}$ & $25,94 \mathrm{c}$ & $14,45 \mathrm{c}$ & 464,27 a & $42,11 \mathrm{a}$ & $0,61 \mathrm{a}$ & $4,17 \mathrm{a}$ & $0,76 \mathrm{a}$ \\
\hline Marcha B2 & $14,97 \mathrm{a}$ & $15,00 \mathrm{a}$ & $14,98 \mathrm{a}$ & $34,79 \mathrm{~b}$ & $16,92 \mathrm{~b}$ & $405,54 \mathrm{~b}$ & $42,06 \mathrm{a}$ & $0,61 \mathrm{a}$ & $4,19 \mathrm{a}$ & $0,75 \mathrm{a}$ \\
\hline Marcha C1 & $14,54 \mathrm{a}$ & $13,44 \mathrm{a}$ & $13,99 \mathrm{a}$ & $40,72 \mathrm{a}$ & $18,79 \mathrm{a}$ & $385,06 \mathrm{~b}$ & $41,99 \mathrm{a}$ & $0,60 \mathrm{a}$ & $4,14 \mathrm{a}$ & $0,77 \mathrm{a}$ \\
\hline \multicolumn{11}{|c|}{ No solo firme e coberto com palha de milho e braquiária } \\
\hline Marcha A3 & $8,94 \mathrm{a}$ & $8,60 \mathrm{a}$ & $8,77 \mathrm{a}$ & $23,78 \mathrm{~b}$ & $12,97 \mathrm{~b}$ & $454,83 \mathrm{a}$ & $41,97 \mathrm{a}$ & $0,60 \mathrm{a}$ & $2,67 \mathrm{a}$ & $0,85 \mathrm{a}$ \\
\hline Marcha B1 & $9,73 \mathrm{a}$ & $9,44 \mathrm{a}$ & $9,58 \mathrm{a}$ & $27,79 \mathrm{~b}$ & $14,10 \mathrm{~b}$ & $425,14 \mathrm{a}$ & $42,02 \mathrm{a}$ & $0,60 \mathrm{a}$ & $2,70 \mathrm{a}$ & $0,84 \mathrm{a}$ \\
\hline Marcha B2 & $10,30 \mathrm{a}$ & $10,60 \mathrm{a}$ & $10,45 \mathrm{a}$ & $34,48 \mathrm{a}$ & $15,91 \mathrm{a}$ & $386,60 \mathrm{~b}$ & $42,04 \mathrm{a}$ & $0,61 \mathrm{a}$ & $2,73 \mathrm{a}$ & $0,83 \mathrm{a}$ \\
\hline Marcha C1 & $9,58 \mathrm{a}$ & $9,50 \mathrm{a}$ & $9,54 \mathrm{a}$ & $41,24 \mathrm{a}$ & $17,81 \mathrm{a}$ & $359,87 \mathrm{~b}$ & $41,98 \mathrm{a}$ & $0,60 \mathrm{a}$ & $2,69 \mathrm{a}$ & $0,84 \mathrm{a}$ \\
\hline \multicolumn{11}{|c|}{ No solo firme e descoberta } \\
\hline Marcha A3 & $6,19 \mathrm{a}$ & $5,97 \mathrm{a}$ & $6,08 \mathrm{a}$ & $25,04 \mathrm{c}$ & $12,88 \mathrm{~b}$ & $429,09 \mathrm{a}$ & $42,04 \mathrm{a}$ & $0,61 \mathrm{a}$ & $2,06 \mathrm{a}$ & $0,89 \mathrm{a}$ \\
\hline Marcha B1 & $6,61 \mathrm{a}$ & $6,35 \mathrm{a}$ & $6,48 \mathrm{a}$ & $27,07 \mathrm{c}$ & $13,49 \mathrm{~b}$ & $415,78 \mathrm{a}$ & $41,99 \mathrm{a}$ & $0,60 \mathrm{a}$ & $2,06 \mathrm{a}$ & $0,89 \mathrm{a}$ \\
\hline Marcha B2 & $7,11 \mathrm{a}$ & $7,43 \mathrm{a}$ & $7,27 \mathrm{a}$ & $37,23 \mathrm{~b}$ & 15,99 a & $358,21 \mathrm{~b}$ & $42,04 \mathrm{a}$ & $0,61 \mathrm{a}$ & $2,08 \mathrm{a}$ & $0,88 \mathrm{a}$ \\
\hline Marcha C1 & $8,81 \mathrm{a}$ & $8,21 \mathrm{a}$ & $8,51 \mathrm{a}$ & $41,67 \mathrm{a}$ & $17,22 \mathrm{a}$ & $344,59 \mathrm{~b}$ & $41,98 \mathrm{a}$ & $0,60 \mathrm{a}$ & $2,11 \mathrm{a}$ & $0,87 \mathrm{a}$ \\
\hline
\end{tabular}

* Médias com letras iguais na coluna não diferem entre si pelo teste de Tukey $(P>0,05)$

9,5\%, valor considerado dentro da faixa correta para o desempenho do trator em solo firme conforme ASAE (1999a).

O consumo de combustível foi maior nas marchas B2 e C1 em comparação com os valores obtidos nas marchas A3 e B1 e a potência na barra de tração também foi maior nas marchas B2 e C1 e estatisticamente semelhante entre elas. Os valores de consumo específico também foram significativamente diferentes entre as marchas. O menor valor desse parâmetro foi obtido na marcha C1 que não diferiu da marcha B2, mas ambos foram estatisticamente menores que os valores das marchas A3 e B1 e estas foram semelhantes entre si. Lopes et al. (2003) também observaram que, em solo firme e coberto com restos vegetais da colheita da soja, o aumento da velocidade resultou em um menor consumo específico de combustível, estando de acordo com os dados obtidos neste trabalho. As demais variáveis não apresentaram diferença significativa entre as marchas.

Da mesma forma que para o solo mobilizado, para o solo firme e coberto com palha de milho e braquiária, o melhor desempenho do trator para tracionar a carga de $25 \mathrm{kN}$ foi obtido na marcha C1 a uma velocidade de $6,0 \mathrm{~km} \mathrm{~h}^{-1}$, aproximadamente.

A patinagem dos rodados dianteiros, traseiros e do trator obtidos no solo firme e descoberto foi semelhante para as quatro marchas, com a média de aproximadamente $7 \%$ (Tabela 6).

O consumo de combustível foi maior nas marchas B2 e C1 em comparação com os valores obtidos nas marchas A3 e B1.

A potência na barra de tração foi maior na marcha C1 em relação às demais, seguida marcha $B 2$ que foi maior para as marchas A3 e B1 e estas, semelhantes entre si.

Observa-se que o menor valor de consumo específico foi obtido na marcha C1 que não diferiu da marcha B2, sendo ambos estatisticamente menores que os valores para as marchas A3 e B1, sendo estas semelhantes entre si.

Também no solo firme e descoberto, as demais variáveis não apresentaram diferença significativa entre as marchas.

No solo firme e descoberto se repetiu o que ocorreu para o solo com a superfície mobilizada e para o solo firme coberto com palha de milho e braquiária, pois o melhor desempenho do trator também foi obtido na marcha C1.

\section{CONCLUSÕES}

1. As condições da superfície do solo interferiram na capacidade do trator em desenvolver a tração, pois a maioria dos parâmetros relacionados com o desempenho apresentou variações estatisticamente significativas ao longo dos ensaios.

2. Na superfície com solo mobilizado o desempenho do trator foi inferior ao obtido no solo firme e no solo coberto com palha de milho e braquiária.

3. O melhor desempenho do trator foi obtido no solo firme e sem cobertura.

4. Entre as quatro marchas estudadas, a marcha C1 forneceu velocidade de, aproximadamente, $6 \mathrm{~km} \mathrm{~h}^{-1}$ e apresentou o melhor desempenho operacional do trator, para a força de $25 \mathrm{kN}$ na barra de tração.

\section{AgRADECIMENTOS}

Ao Conselho Nacional de Pesquisa e Desenvolvimento Tecnológico - CNPq, Brasília, Brasil.

\section{LITERATURA CITADA}

ASAE - American Society of Agricultural Engineers. Agricultural Machinery Management. EP 496.2. In: ASAE Standards: Standards engineering practices data. St. Joseph: American Society of Agricultural Engineers, 1999a. p.353-358. 
ASAE - American Society of Agricultural Engineers. Agricultural Machinery Management Data. D 497.4. In: ASAE Standards: Standards engineering practices data. St. Joseph: American Society of Agricultural Engineers, 1999b. p.359-366.

Banzatto, D. A.; Kronka, S. E. Experimentação agrícola. 3.ed. Jaboticabal: FUNEP, 1995. 247p.

Brixius W. W. Traction prediction equation for bias ply tires. St. Joseph: ASAE Paper, 1987. p.83-1067.

Cordeiro M. A. L. Desempenho de um trator agrícola em função do pneu, da lastragem e da velocidade de deslocamento. Botucatu, FCA/UNESP, 2000. 153p. Tese Doutorado

EMBRAPA - Empresa Brasileira de Pesquisa Agropecuária. Centro Nacional de Pesquisa de Solos. Manual de métodos de análise de solo. 2.ed. Rio de Janeiro: EMBRAPA/CNPS, 1997. 212p.

EMBRAPA - Empresa Brasileira de Pesquisa Agropecuária. Centro Nacional de Pesquisa de Solos. Sistema brasileiro de classificação de solos. Rio de Janeiro: EMBRAPA/CNPS, 1999. 412p.

Gabriel Filho, A.; Silva, S. L.; Modolo, A. J.; Silveira, J. C. Desempenho de um trator operando em solo com diferentes tipos de cobertura vegetal. Engenharia Agrícola. v.24, n.3, p.781-789, 2004.

Gomes, F. P. Curso de estatística experimental. 10.ed. Piracicaba: ESALQ/USP, 1982. 430p.
Gomes, F. P.; Garcia, C. H. Estatística aplicada a experimentos agronômicos e florestais: Exposição com exemplos e orientações para uso de aplicativos. Piracicaba: FEALQ, 2002. 309p.

Grotta D. C. C. Desempenho de um trator agrícola em operação de gradagem utilizando biodiesel etílico filtrado de óleo residual como combustível. Jaboticabal: UNESP, 2003. 58p. Dissertação Mestrado

Kiehl, E. J. Manual de edafologia. São Paulo: CERES, 1979. 267p.

Lanças, K. P. Desempenho operacional de pneus radiais em função da pressão de inflação, da lastragem e do deslizamento das rodas de tratores agrícolas. Botucatu: FCA/UNESP. 1996. 172p. Tese Livre Docência

Lopes, A.; Lanças K. P.; Furlani, C. E. A.; Nagaoka, A. K.; Castro Neto, P.; Grotta, D. C. C. Consumo de combustível de um trator em função do tipo de pneu, da lastragem e da velocidade de trabalho. Revista Brasileira de Engenharia Agrícola e Ambiental, v.7, n.2, p.382-386, 2003.

Wismer, R. D.; Luth, H. J. Off-road traction prediction for wheeled vehicles. Transactions of the ASAE, v.17, n.1, p.8-14, 1974.

Yanai, K.; Silveira, G. M.; Lanças, K. P.; Corrêa. I. M.; Maziero, J. V. G. Desempenho operacional de trator com e sem acionamento da tração dianteira auxiliar. Pesquisa Agropecuária Brasileira, v.34, n.8, p.1427-1434, 1999.

Zoz, F. M. Predicting tractor field performance (updated). St. Joseph: ASAE, 1987. 12p. ASAE Paper n.871623 